\title{
Magnesium deficiency: a possible cause of thiamine refractoriness in Wernicke-Korsakoff encephalopathy
}

\author{
D. C. TRAVIESA \\ From the Department of Neurology, University of Miami School of Medicine, \\ Miami, Florida, U.S.A.
}

SYNOPSIS The determination of blood transketolase before and serially after thiamine administration, and the response of clinical symptomatology after thiamine are reported in two normomagnesaemic patients and one hypomagnesaemic patient with acute Wernicke-Korsakoff encephalopathy. The response of the depressed blood transketolase and the clinical symptoms was retarded in the hypomagnesaemic patient. Correction of hypomagnesaemia was accompanied by the recovery of blood transketolase activity and total clearing of the ophthalmoplegia in this patient, suggesting that hypomagnesaemia may be a cause of the occasional thiamine refractoriness of these patients.

Previous studies have shown that the clinical entity of Wernicke-Korsakoff encephalopathy is related to an exclusive deficiency of thiamine (Phillips et al., 1952). Furthermore, improvement in clinical symptoms, once the syndrome has developed, occurs only with the repletion of thiamine. It is this obvious and seemingly pure causal relationship of thiamine deficiency and Wernicke-Korsakoff encephalopathy that necessitates the total understanding of thiamine metabolism in the human if this disease is to be fully understood.

Both pyruvate decarboxylase and transketolase enzymes are thiamine pyrophosphate dependent (Horecker and Smyroniotis, 1953). It has been shown, however, that in the central nervous system of rats deprived of thiamine, pyruvate decarboxylase activity is apparently refractory to thiamine depletion, whereas a rapid diminution of transketolase activity is earliest and most pronounced in the lateral vestibular nuclei of thiamine deficient rats (Dreyfus and Hauser, 1965). If thiamine deprivation is prolonged, the initial decrease in transketolase activity is followed by stereotyped lesions in the lateral

Address for reprints: Dr D. C. Traviesa, Department of Neurology, Suite 448, Woodard Bidg, Jackson Memorial Hospital, 1700 N.W 10th Avenue, Miami, Florida 33136, U.S.A. vestibular nuclei (Prickett, 1934; Dreyfus and Victor, 1961 ; Dreyfus, 1965).

Blood transketolase activity is markedly reduced in patients with Wernicke-Korsakoff encephalopathy and serial assays in these patients usually reveal a rapid and essentially complete recovery of the reduced blood transketolase activity after the parental administration of thiamine (Brin, 1962; Dreyfus, 1962). Because of the seemingly simultaneous recovery of enzyme activity and clinical improvement in the ophthalmoplegia, it has been hypothesized that the dysfunction of the transketolase enzyme system plays a role in the pathogenesis of Wernicke-Korsakoff encephalopathy.

Transketolase is an enzyme in the hexose monophosphate shunt which requires not only thiamine pyrophosphate but also magnesium as a co-factor. Wernicke-Korsakoff encephalopathy is a disease of the central nervous system in which there is considerable evidence that dysfunction of the transketolase enzyme system plays an aetiological role; however, the effect of hypomagnesaemia on the response to thiamine of transketolase enzyme activity and clinical symptomatology in patients with Wernicke- 
Korsakoff encephalopathy has never been investigated.

The purpose of this paper is to report serial determinations of blood transketolase activity before and after thiamine and the response of clinical symptoms to thiamine in two normomagnesaemic and one hypomagnesaemic patient with unequivocal WernickeKorsakoff encephalopathy. The possible role of hypomagnesaemia in the therapy of WernickeKorsakoff encephalopathy will be discussed.

The three patients had the following historical and physical findings in common. All three patients were severe chronic alcoholics with a history obtained from relatives or friends of extreme malnutrition of at least four months' duration before admission. The common chief complaint of the three patients was difficulty in walking. Upon admission and before thiamine administration, the patients showed all the salient clinical features of Wernicke-Korsakoff encephalopathy: ophthalmoplegia, nystagmus, ataxia, and mental disturbances (Table 1).

All three patients showed diminution to pain, touch, and vibration in both lower extremities in the typical stocking-type distribution. After thiamine administration, the symptoms and signs improved except for the Korsakoff's psychosis in patients nos 2 and 3. The global confusional state in patient no. 1 improved and he was left with a defective memory for recent events. The ophthalmoplegia in the three patients cleared completely in 10, six, and 48 hours respectively and nystagmus and ataxia improved to a variable degree and over a longer period of time after thiamine administration.
METHOD

A sample of blood was drawn from each patient for determination of serum magnesium, which was considered an estimation of magnesium depletion.

Seven millilitres of blood were drawn from each patient and placed in heparinized tubes before and at four and 12 hours after administration of $100 \mathrm{mg}$ thiamine intramuscularly. One $7 \mathrm{ml}$ sample was also drawn at 36 hours from patient no. 3, who was hypomagnesaemic. This patient received a total of $6 \mathrm{~g}$ of $\mathrm{MgSO}_{4}$ intramuscularly in three divided doses over a 12 hour period beginning 14 hours after intramuscular thiamine was administered. All samples of heparinized blood were centrifuged immediately. The plasma was removed and a volume of distilled water equal to the packed erythrocyte volume was added to the erythrocytes to form a haemolysate. These were frozen and later used for determination of transketolase activity. Blood transketolase activity in six healthy normal subjects and in all experimental samples collected was determined by the method described by Brin (1966). The buffer solution in this study contained no magnesium.

Haemolysate, $0.5 \mathrm{ml}$ from each sample, was placed in two tubes. Tube 1 served as the blank and contained $0.65 \mathrm{ml}$ of buffer. Tube 2 contained $0.45 \mathrm{ml}$ of buffer and was incubated at $38^{\circ} \mathrm{C}$ for 30 minutes followed by the addition of $0.2 \mathrm{ml}$ of a $7.0 \mathrm{mg} / \mathrm{ml} \mathrm{solu}$ tion of sodium ribose-5-phosphate. This mixture was incubated for one hour at $38^{\circ} \mathrm{C}$, followed by termination of the reaction by the addition to both tubes of $6.0 \mathrm{ml} \mathrm{7.5 \%}$ trichloracetic acid. The tubes were centrifuged at $3000 \mathrm{rpm}$ for 10 minutes and $1.0 \mathrm{ml}$ of the clear supernatant as well as $100 \mu \mathrm{g} / \mathrm{ml}$ and $50 \mu \mathrm{g} /$ $\mathrm{ml} \mathrm{D}$-glucose standards were used to determine spectrophotometrically the total hexose produced by the anthrone method described by Brin (1966). Transketolase activity was expressed in $\mu \mathrm{g}$ hexose per ml haemolysate per hour.

TABLE 1

CLINICAL DETAILS OF THREE PATIENTS

\begin{tabular}{|c|c|c|c|c|}
\hline Patient & Ophthalmoplegia & Nystagmus & Ataxia & Mental disturbance \\
\hline 1 (K.D.) & $\begin{array}{l}\text { 1. Bilateral horizontal gaze palsy } \\
\text { 2. Upgaze palsy }\end{array}$ & Upbeating vertical jerk & Trunk and lower limbs & Acute confusional state \\
\hline 2 (D.C.) & Bilateral 6th nerve palsy & Horizontal jerk & Trunk and lower limbs & Korsakoff's psychosis \\
\hline 3 (B.C.) & $\begin{array}{l}\text { 1. Right } 6 \text { th nerve palsy } \\
\text { 2. Left horizontal gaze palsy }\end{array}$ & $\begin{array}{l}\text { Horizontal jerk } \\
\text { Down beat vertical jerk }\end{array}$ & Trunk and lower limbs & Korsakoff's psychosis \\
\hline
\end{tabular}


TABLE 2

SERIAL BLOOD TRANSKETOLASE ACTIVITY BEFORE AND AFTER THIAMINE, SERUM MAGNESIUM LEVELS, AND DURATION OF OPHTHALMOPLEGIA AFTER THIAMINE IN THE THREE SUBJECTS

\begin{tabular}{|c|c|c|c|c|}
\hline Patient & $\begin{array}{c}\text { Hour } \\
\text { post-thiamine }\end{array}$ & $\begin{array}{l}\text { Blood transketolase activity } \\
\frac{\mu \mathrm{g} \text { hexose }}{\mathrm{ml} \text { haemolysate }} / \mathrm{hr}\end{array}$ & $\begin{array}{c}\text { Serum mg } \\
\text { (Nl. } 2-3 \mathrm{mg} / 100 \mathrm{ml})\end{array}$ & $\begin{array}{c}\text { Duration of ophthalmoplegia } \\
\text { after thiamine administration } \\
\qquad(\text { hr })\end{array}$ \\
\hline Normal subjects (6) & & $1070 \pm 80 \mathrm{SD}$ & & \\
\hline 1 & $\begin{array}{c}\text { Before } \\
4 \\
12\end{array}$ & $\begin{array}{r}605 \\
714 \\
1039\end{array}$ & $\cdots \cdots \cdot 2 \cdot 3$ & 10 \\
\hline 2 & $\begin{array}{c}\text { Before } \\
4 \\
12\end{array}$ & $\begin{array}{l}490 \cdots \cdots \cdots \cdots \cdots \cdots \\
617 \\
938\end{array}$ & $\cdots \cdots \cdots 2 \cdot 4$ & 6 \\
\hline 3 & $\left.\begin{array}{c}\text { Before } \\
4 \\
12 \\
36\end{array}\right]$ & 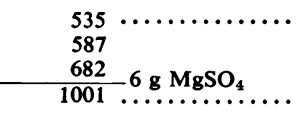 & $\begin{array}{l}\cdots \cdots \cdots \cdot 1 \cdot 2 \\
\cdots \cdots \cdots \cdot 3 \cdot 0\end{array}$ & 48 \\
\hline
\end{tabular}

RESULTS (Table 2)

The blood transketolase activity in the six normal subjects averaged $1070 \mu \mathrm{g}$ hexose $/ \mathrm{ml}$ per hour. The blood transketolase activity of the three patients with Wernicke-Korsakoff encephalopathy before the administration of thiamine was markedly reduced. The response of the enzyme activity to parenteral thiamine was essentially complete in the normomagnesaemic patients 12 hours after intramuscular thiamine. Furthermore, the ophthalmoplegia described earlier in these patients was completely gone in 10 and six hours respectively after thiamine administration. In contrast, the response of blood transketolase activity and the ophthalmoplegia were retarded at 12 hours postthiamine administration in the hypomagnesaemic patient. The blood transketolase was $692 \mu \mathrm{g} / \mathrm{ml}$ and the left gaze palsy and right sixth nerve palsy were not improved at 12 hours. Not until the hypomagnesaemia was corrected in this patient by the administration of $\mathrm{MgSO}_{4}$ did the blood transketolase activity become normal and the ophthalmoplegia clear completely.

It is recognized that the small number of patients-and, in particular the fact that only one patient with hypomagnesaemia was studied -makes it difficult to draw firm conclusions from these observations. The different response of the hypomagnesaemic patient to thiamine and the apparent influence of added magnesium is sufficiently striking to warrant its presentation in support of a hypothesis that normal tissue magnesium is necessary for the thiamine response in patients with Wernicke-Korsakoff encephalopathy.

\section{DISCUSSION}

Experimental studies on the rat have shown that there is an interdependence between magnesium and thiamine in the body (Zieve et al., 1968a). Transketolase activity in both the liver and blood of thiamine depleted hypomagnesaemic rats is markedly depressed and the recovery of the enzyme activity to thiamine is incomplete. Body growth is retarded in similar rats despite the administration of thiamine (Zieve et al., 1968a). The mechanism by which magnesium deficiency interferes with the recovery of transketolase activity is not clear. Several hypotheses have been given. The simple unavailability of magnesium for the reaction has been considered unlikely, since the in vitro addition of magnesium at the time of transketolase assay does not increase activity (Zieve et al., 1968b). Another hypothesis is that there is a lack of pentose substrate for the reaction, because of the magnesium requirement for substrate formation (Zieve et al., 1968b).

In the two normomagnesaemic patients reported here there was complete improvement in ophthalmoplegia in 10 and six hours respectively and a manifest improvement 45 minutes after thiamine administration. The nystagmus became 
more pronounced as the ophthalmoplegia improved and ataxia and mental disturbances were much more refractory to therapy. In contrast, the hypomagnesaemic patient with WernickeKorsakoff encephalopathy showed no improvement of ophthalmoplegia 12 hours after thiamine. $\mathrm{MgSO}_{4}$ therapy was begun 14 hours after thiamine administration and the ophthalmoplegia subsequently reversed over the next 34 hours. Therefore, at least in these patients, clinical improvement seemed to have been correlated with the level of blood transketolase activity.

The presence of cirrhosis has been shown to be associated with a delayed response of both blood transketolase activity and lateral rectus palsy in patients with Wernicke-Korsakoff encephalopathy, presumably because of the inability to phosphorylate thiamine in hepatic disease (Cole et al., 1969). Although hepatic enzymes were initially elevated in the three patients reported here, all enzymes became normal after three to six days of vitamins and diet. Only patient 1 had an elevated prothrombin time which reverted to normal four days after hospitalization. The physical examination of the hypomagnesaemic patient 3 revealed no evidence of hepatomegaly, ascites, spinal angiomata or dilated veins on the abdominal wall. Liver function tests done on the first hospital day demonstrated mild elevation of serum glutamic oxalacetic transaminase (110 $\mathrm{mU} / \mathrm{ml})^{*}$ and lactate dehydrogenase $(220 \mathrm{mU} / \mathrm{ml})$ but normal alkaline phosphatase $(65 \mathrm{mU} / \mathrm{ml})$, total bilirubin $(1.0 \mathrm{mg} / 100 \mathrm{ml})$, albumin $(3.7 \mathrm{mg} /$ $100 \mathrm{ml})$ and prothrombin time $(11.7 \mathrm{~s}$; control $11.6 \mathrm{~s})$. Liver function tests were normal on the third hospital day and throughout the rest of the hospital course. Cirrhosis, therefore, was an unlikely cause for the blood transketolase and ophthalmoplegia refractoriness occurring in this patient.

There is evidence suggesting that depressed activity of transketolase in the central nervous system is related aetiologically to the lesions produced by the deficiency of thiamine. Furthermore, the demonstration of both trans-

* $\mathrm{mU}=$ milli-international units. ketolase and clinical refractoriness to thiamine in the hypomagnesaemic patient, as well as improvement in symptoms and recovery of transketolase activity after the correction of hypomagnesaemia in this patient, supports the hypothesis that hypomagnesaemia is a cause of the thiamine refractoriness that is seen occasionally in patients with acute Wernicke-Korsakoff encephalopathy.

The author wishes to express thanks to Dr Barry Fistoff and Dr Peritz Scheinberg for their encouragement and help.

\section{REFERENCES}

Brin, M. (1962). Erythrocyte transketolase in early thiamine deficiency. Annals of the New York Academy of Sciences, 98, 528-541.

Brin, M. (1966). Transketolase: clinical aspects. In Methods in Enzymology, vol. 9, pp. 506-514. Edited by S. P. Kolwick and N. O. Kaplan. Academic Press: New York.

Cole, M., Turner, A., Frank, O., Baker, H., and Leevy, C. M. o (1969). Extraocular palsy and thiamine therapy i⿱丆贝 Wernicke's encephalopathy. American Journal of Clinica'চ Nutrition, 22, 44-51.

Dreyfus, P. M. (1962). Clinical application of blood trans@ ketolase determinations. New England Journal of Medicine 267, 596-598.

Dreyfus, P. M. (1965). The regional distribution of trans ketolase in the normal and the thiamine deficient nervous system. Journal of Neuropathology and Experimenta $\overline{5} . \overrightarrow{\mathrm{C}}$ Neurology, 24, 119-129.

Dreyfus, P. M., and Hauser, G. (1965). The effect of thiamine deficiency on the pyruvate decarboxylase system of the central nervous system. Biochimica et Biophysica Acta, 104 78-84.

Dreyfus, P. M., and Victor, M. (1961). Effects of thiamine deficiency on the central nervous system. American Journal of Clinical Nutrition, 9, 414-425.

Horecker, B. L., and Smyrniotis, P. Z. (1953). The coenzyme function of thiamine pyrophosphate in pentose metabolism. Journal of the American Chemical Society, 75, 10091010.

Phillips, G. B., Victor, M., Adams, R. D., and Davidsen, C. S. (1952). A study of the nutritional defect in Wernicke's syndrome. Journal of Clinical Investigation, 31, 859-871.

Prickett, C. O. (1934). The effect of a deficiency of vitamin $\mathbf{B}^{1}$ upon the central and peripheral nervous systems of the rat. American Journal of Physiology, 107, 459-470.

Zieve, L., Doizaki, W. M., and Stenroos, L. E. (1968a). Effect of magnesium deficiency on growth response to thiamine of thiamine-deficient rats. Journal of Laboratory and Clinical Medicine, 72, 261-267.

Zieve, L., Doizaki, W. M., and Stenroos, L. E. (1968b). Effect of magnesium deficiency on blood and liver transketolase activity and on the recovery of enzyme activity in thiamine-deficient rats receiving thiamine. Journal of Laboratory and Clinical Medicine, 72, 268-277. 